\title{
Prevalence, aetiologies and prognosis of the symptom cough in primary care: a systematic review and meta-analysis
}

\author{
Milena Bergmann* ${ }^{*}$, Jörg Haasenritter, Dominik Beidatsch, Sonja Schwarm, Kaja Hörner, Stefan Bösner, \\ Paula Grevenrath, Laura Schmidt, Annika Viniol, Norbert Donner-Banzhoff and Annette Becker
}

\begin{abstract}
Background: Cough is a relevant reason for encounter in primary care. For evidence-based decision making, general practitioners need setting-specific knowledge about prevalences, pre-test probabilities, and prognosis. Accordingly, we performed a systematic review of symptom-evaluating studies evaluating cough as reason for encounter in primary care.
\end{abstract}

Methods: We conducted a search in MEDLINE and EMBASE. Eligibility criteria and methodological quality were assessed independently by two reviewers. We extracted data on prevalence, aetiologies and prognosis, and estimated the variation across studies. If justifiable in terms of heterogeneity, we performed a meta-analysis.

Results: We identified 21 eligible studies on prevalence, 12 on aetiology, and four on prognosis. Prevalence/incidence estimates were 3.8-4.2\%/12.5\% (Western primary care) and 10.3-13.8\%/6.3-6.5\% in Africa, Asia and South America. In Western countries the underlying diagnoses for acute cough or cough of all durations were respiratory tract infections (73-91.9\%), influenza (6-15.2\%), asthma (3.2-15\%), laryngitis/tracheitis (3.6-9\%), pneumonia (4.0-4.2\%), COPD (0.5-3.3\%), heart failure (0.3\%), and suspected malignancy (0.2-1.8\%). Median time for recovery was 9 to 11 days. Complete recovery was reported by 40.2- $67 \%$ of patients after two weeks, and by $79 \%$ after four weeks. About $21.1-35 \%$ of patients re-consulted; $0-1.3 \%$ of acute cough patients were hospitalized, none died. Evidence is missing concerning subacute and chronic cough.

Conclusion: Prevalences and incidences of cough are high and show regional variation. Acute cough, mainly caused by respiratory tract infections, is usually self-limiting (supporting a "wait-and-see" strategy). We have no setting-specific evidence to support current guideline recommendations concerning subacute or chronic cough in Western primary care. Our study presents epidemiological data under non non-pandemic conditions. It will be interesting to compare these data to future research results of the post-pandemic era.

Keywords: Cough, General practice, Primary care, Diagnosis, Prevalence, Aetiology, Prognosis, Systematic review, Symptom-evaluating study

*Correspondence: milena.bergmann@posteo.de Department of General Practice / Family Medicine, University of Marburg, Karl-von-Frisch-Str. 4, 35043 Marburg, Germany

\section{Background}

Nearly every person has experienced an episode of cough in their lifetime. Based on population, the prevalence of cough in Europe and the USA is 9-33\% [1]. Severe cough can significantly impair health-related quality of life and be linked i.a. to depression, urinary incontinence, syncope, 
social embarrassment, sleep disturbance and depression $[2,3]$. While most episodes of cough are benign and selflimiting, in some cases the symptom points to severe illnesses like pneumonia or lung cancer [4].

General practitioners (GPs) play an important role as gatekeepers. Based on history and examination, they triage self-limiting symptoms and severe, possibly life-limiting diseases and decide about further testing, treatment and referral. To support the clinical decision-making process, GPs need to know the percentage distribution of possible aetiologies in order to correctly interpret the clinical signs. This is different from inpatient settings because patients in family practices, which are the first point of contact, are more likely to have an uncomplicated cause of their cough than are patients in a hospital. Nevertheless, family physicians need to work with the pre-test probabilities of potentially dangerous illnesses in their setting, and also the most likely prognosis of their patients.

Evidence is given by cough guidelines [5-7]. However, data often derives from secondary or tertiary care settings which show different pre-test probabilities. Symptom-evaluating studies in primary care are needed for a more rational and evidence-based approach in settingspecific decision making [8].

Therefore, we performed a systematic review aiming to answer the following research questions: (1) What is the frequency / prevalence of cough in primary care? (2) What are the underlying aetiologies and their frequencies? and (3) What is the prognosis of patients presenting with cough in primary care?

\section{Methods}

\section{Data sources and search strategy}

We conducted a systematic review including all studies evaluating the symptom "cough" as a reason for encounter in primary care. The methods were based on the PRISMA statement [9] and on recommendations for symptom-evaluating studies by Donner-Banzhoff et al. 2001 [8]. The study methods including eligibility criteria and analysis were pre-specified in a protocol. Our research group applied the same methods for the symptoms tiredness, abdominal pain, headache, chest pain, dyspnoea, dizziness, and back pain [10-14].

We performed a systematic search in MEDLINE (2012) and EMBASE (2015), updated 2019 resp. 2020, addressing publications in English, German, and French. A snowball search included the reference lists of all articles and reviews. The search syntax combined the terms "cough" AND "general practice" in various notations OR their MESH terms in title or abstract. Alternatively, we considered papers on "cough" published in journals representing primary care research OR papers in which the term "primary care" appeared in different notations in the affiliation of at least the main author. The entire search syntax can be found in Additional File 1.

\section{Study selection and data extraction}

We screened titles and abstracts and the eligible full text articles with respect to the criteria given in Table 1. Eligible studies focusing solely on children were excluded from data analysis and will be published elsewhere.

All steps of the selection process (except its update in 2019/2020) were performed and documented by two reviewers (MB, DB/SS) working independently. In case of disagreement, the full text evaluation was revised, inclusion criteria were discussed, and, if necessary, an expert $(\mathrm{AB})$ was consulted.

We extracted bibliographic data (author, publication year, title, journal), country, inclusion criteria, definition of cough, characteristics of physicians and practices, study design, sample size and study duration. For outcomes we extracted data concerning prevalence/incidence, underlying aetiologies and the prognosis of cough.

Table 1 Inclusion and exclusion criteria for screening of titles/abstracts and eligible full text articles

\begin{tabular}{|c|c|c|c|}
\hline Category & Inclusion criteria & Exclusion criteria & Assessment in \\
\hline (1) Study design & $\begin{array}{l}\text { original quantitative study design regardless of study } \\
\text { quality, risk of bias or type of data assessment }\end{array}$ & $\begin{array}{l}\text { qualitative studies, case reports, reviews, full text was } \\
\text { not available }\end{array}$ & $\begin{array}{l}\text { titles/abstracts, } \\
\text { eligible full text articles }\end{array}$ \\
\hline (2) Setting & primary care / general practice & $\begin{array}{l}\text { secondary or tertiary care, emergency departments, } \\
\text { out-of-hours-services, population-based settings }\end{array}$ & $\begin{array}{l}\text { titles/abstracts, } \\
\text { eligible full text articles }\end{array}$ \\
\hline (3) Symptom & $\begin{array}{l}\text { cough as the primary or secondary reason for the } \\
\text { consultation }\end{array}$ & $\begin{array}{l}\text { patients were systematically asked whether they are } \\
\text { coughing }\end{array}$ & $\begin{array}{l}\text { titles/abstracts, } \\
\text { eligible full text articles }\end{array}$ \\
\hline (4) Selection & $\begin{array}{l}\text { unselected study population regarding the likeli- } \\
\text { hood of a specific condition as the underlying } \\
\text { aetiology }\end{array}$ & $\begin{array}{l}\text { specific groups of cough patients were explicitly } \\
\text { included or excluded (e.g. cough due to respira- } \\
\text { tory tract infections, a mandatory combination of } \\
\text { cough with another symptom or an exclusion of } \\
\text { patients with underlying conditions like asthma } \\
\text { or COPD) }\end{array}$ & eligible full text articles \\
\hline (5) Outcomes & $\begin{array}{l}\text { data on incidence, prevalence, aetiology or the } \\
\text { prognosis of cough }\end{array}$ & $\begin{array}{l}\text { no data on incidence, prevalence, aetiology or the } \\
\text { prognosis of cough }\end{array}$ & eligible full text articles \\
\hline
\end{tabular}


Seven study authors were contacted to complement published data. In case of multiple publications, we extracted data from all eligible reports.

\section{Assessment of risk of bias}

Due to lack of standardized guidelines for assessing risk of bias in symptom-evaluating studies, we followed the criteria published by Donner-Banzhoff et al. [8], which entail four domains with pre-specified key questions related to the potential of bias. Domain A and B refer to all studies dealing with the selection of patients and physicians (description of symptom, inclusion criteria, recruitment, multicentricity), data collection, and patient flow (study design, dropouts). Domain $\mathrm{C}$ refers to the aetiological outcomes (the definition of aetiological categories, diagnostic workup). Domain D assesses the quality of the prognostic data (definition of the outcome, inclusion of a comparison group, prognostic workup). Again, two reviewers (MB, $\mathrm{KH})$, working independently, assessed the risk of bias.

\section{Data analysis}

We calculated proportions (with a confidence interval of 95\%) on prevalence/incidence data and the underlying aetiologies. If sensible, a meta-analysis was performed. To visualize probability estimates and between-study variation of our data, we used forest plots. To ensure comparability, we grouped studies according to the estimates' denominators, the duration of cough (both pre-specified) and regional characteristics (post hoc).

For meta-analysis we used the random effects model (assuming a distribution of effects across studies) to weigh estimates of studies in proportion to their significance [15].

Outcomes vary due to differences in study design and bias (methodological heterogeneity) as well as in study population, inclusion criteria, healthcare system and diagnostic workup (clinical heterogeneity) [15]. To quantify heterogeneity, we used $x^{2}, \mathrm{p}$-value, and $\mathrm{I}^{2}$. A high $\mathrm{x}^{2}$ and a low p-value correlate with a heterogeneity beyond chance; $\mathrm{I}^{2}$ describes the portion of variability that is not due to chance [15].

There were only a few heterogeneous studies providing evidence of prognosis for cough. Therefore these results were analyzed descriptively.

For statistical analysis we used the software R (R Foundation for statistical Computing, Vienna, Austria, version 3.4.4) and RStudio V (RStudio, Inc., version 1.1.442).

\section{Results}

\section{Search results and study selection}

We identified 2,985 references in MEDLINE, 2,719 additional references in EMBASE, and 19 by snowball searching. Screening of titles/abstracts and full texts identified 73 eligible references, of which 60 publications (31 studies) reported data on adults or on patients of all age groups. Of these, 22 provided data on prevalence of cough in primary care, 12 on aetiology and 4 on prognosis. Further details are presented in Fig. 1.

\section{Included studies}

Most studies were conducted in Western countries: In Europe $(n=12)$, in North America $(n=6)$, in both Europe and North America $(n=2)$, and in Australia $(n=1)$. Five studies collected data in Asia, four in Africa, and one in South America, Africa and Asia. Time of publication varied between 1969 and 2018. Studies included 32 to 158,863 patients, 121 to 337,348 consultations, and 385 to 284,348 reasons for encounters. Forty-two per cent to $75 \%$ of study populations were women; the overall age ranged from 0 to 103 years (the mean age was 24 to 50 years). One study recruited only patients 65 years and above. Except for one, the study population was recruited prospectively. Further details on study characteristics are presented in Table 2.

\section{Assessment of risk of bias}

Depending on the selection of patients and GPs (Domain A) most studies had a low risk of substantial variation and of risk of bias. Referring to data collection and patient flow (Domain B) the risk of bias was found to be low in most studies $(n=20)$, and none had a high risk of bias. In diagnostic workup (Domain $C$ ) most showed a high risk of bias $(n=7)$. The risk of bias in the prognostic workup (Domain D) was low in one study, unclear in another, and had different assessments in two studies, depending on the prognostic category. Only seven studies had an overall low risk of bias. A summary is presented in Table 3; detailed methodological description and risk of bias can be found in Additional File 2.

\section{Prevalence and incidence}

Twenty-two studies presented outcomes on the prevalence of cough; nine of these show a low risk of bias. Figure 2 presents the prevalences and incidences of cough in Western primary care. Incidental consultations showed about three times as many estimates in comparison with prevalences. Outliers were characterized by study populations recruited in a single primary care practice with one or two GPs $[38,50]$ or by excluding consultations for cough of $<2$ and $>15$ weeks duration [54]. Comparably low prevalences were seen in a study population of patients aged $\geq 65$ years [51] and in studies including not only consultations for symptoms, but also for prescriptions, follow-up visits, tests, procedures and administrative visits to the denominator $[49,50]$. 


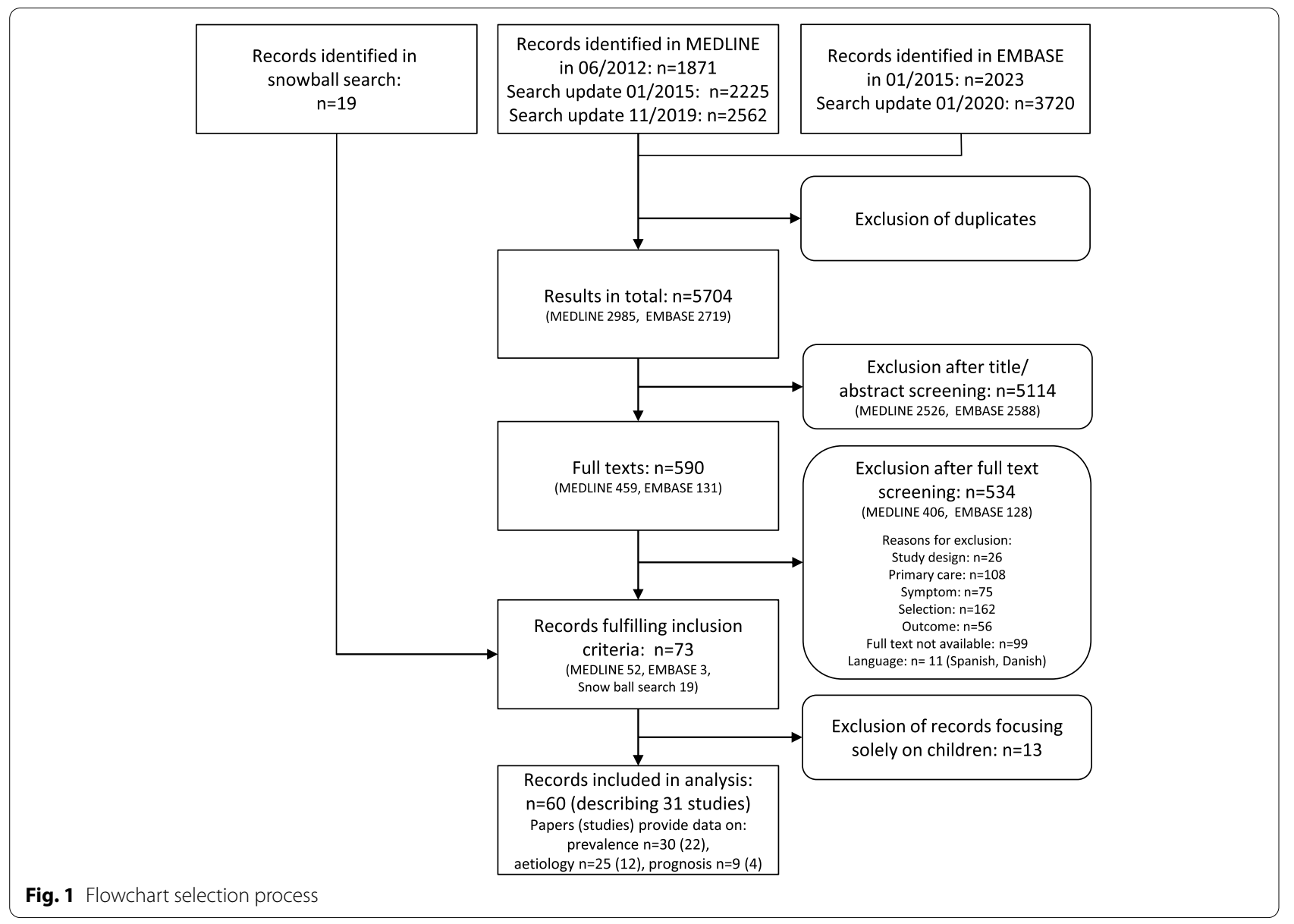

Studies with data collection in African, Asian and South American primary care settings show higher estimates of prevalence $(13.8 \%$ for reasons for encounter and $10.3 \%$ for patients), while they show lower estimates of incidence (6.3\% for consultations) (see Additional File $3)$. The presented estimates show a high heterogeneity across studies, indicated by high values of $\mathrm{I}^{2}$ and $x^{2}$.

\section{Aetiology}

Twelve studies assessed data on the aetiology of cough in primary care. Data referred to different durations of cough and a wide spectrum of differential diagnoses. Mostly, the given aetiologies were the working or presumptive diagnoses by the treating GPs, which correlate with a high risk of bias in the diagnostic workup process. No study had a low risk of bias in all categories. As there were differing denominators (reasons for encounter, (incidental) consultations, episodes of care, patients), no meta-analysis was performed and data is presented in forest plots (Fig. 3, Fig. 4). Data on acute cough and cough of all durations were collected in North America and Europe. The most frequent underlying conditions in acute cough were respiratory tract infections (ranging from 73-91.9\%) and in cough of all durations, bronchitis/ bronchiolitis (25.4-50.2\%). Potentially serious diseases like pneumonia, chronic obstructive pulmonary disease (COPD), heart failure or suspected malignancy were rare. Findings on subacute/chronic cough derived from a study conducted in Zimbabwe (with an HIV prevalence of 83\%) [45] and Malaysia [48], showing high prevalences of tuberculosis $(6.0-43.0 \%)$ and pneumonia $(2.8-16.0 \%)$ (see Additional File 4). The results of these studies are not applicable to the context of Western countries. The high quality study by Munyati et al. [45] is based on a sample with $83 \%$ HIV positive patients; the work by Nantha et al. [48] lacks sufficient information to estimate the risk of bias. In the foremost aetiological categories, we found substantial heterogeneity across studies, indicated by high values of $\mathrm{I}^{2}$ and $\chi^{2}$.

\section{Prognosis}

Four studies assessed prognostic outcomes, one with an overall low risk of bias. Studies included patients with acute cough of up to one [35] or four weeks [20, 30-34, 


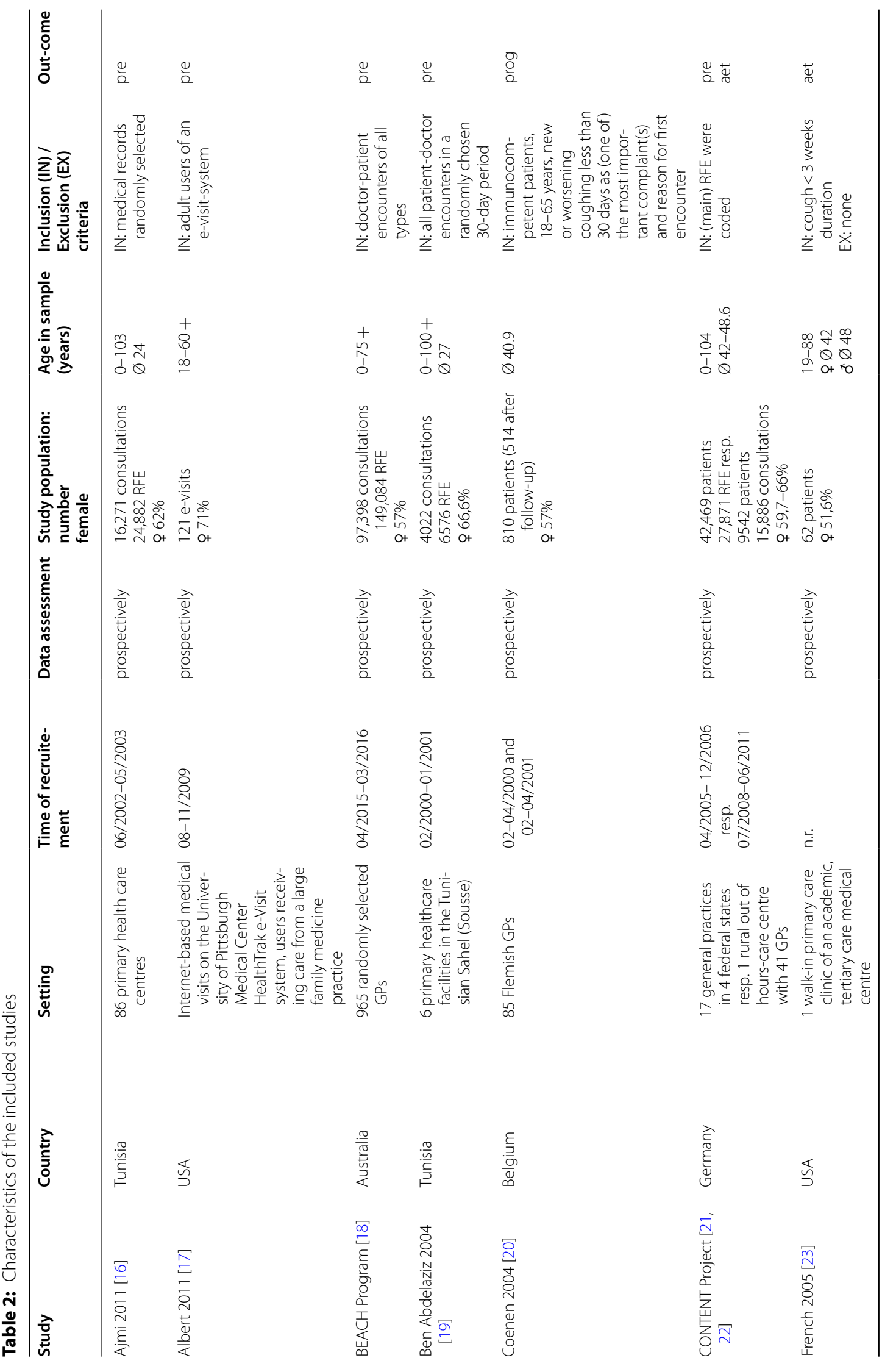




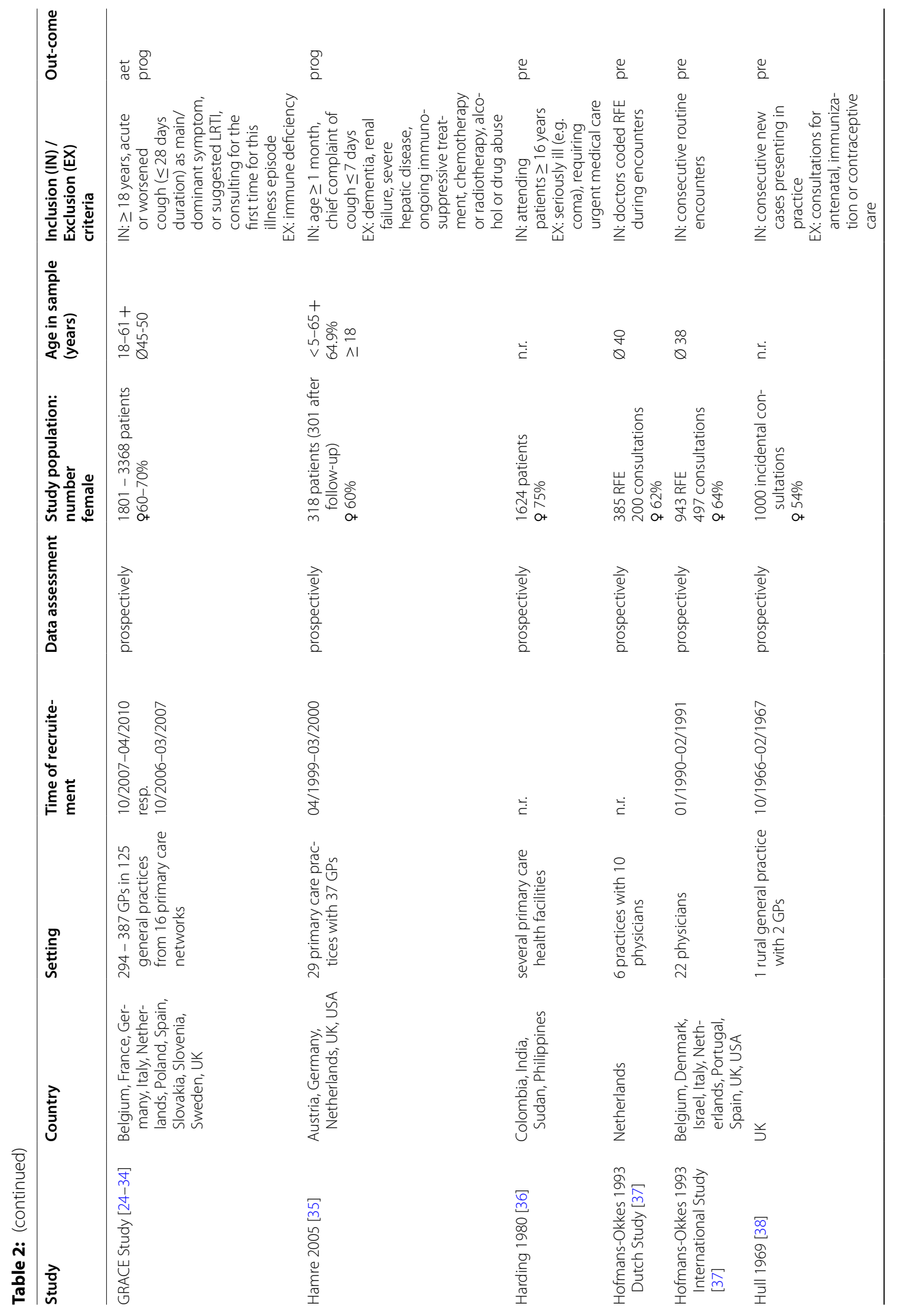




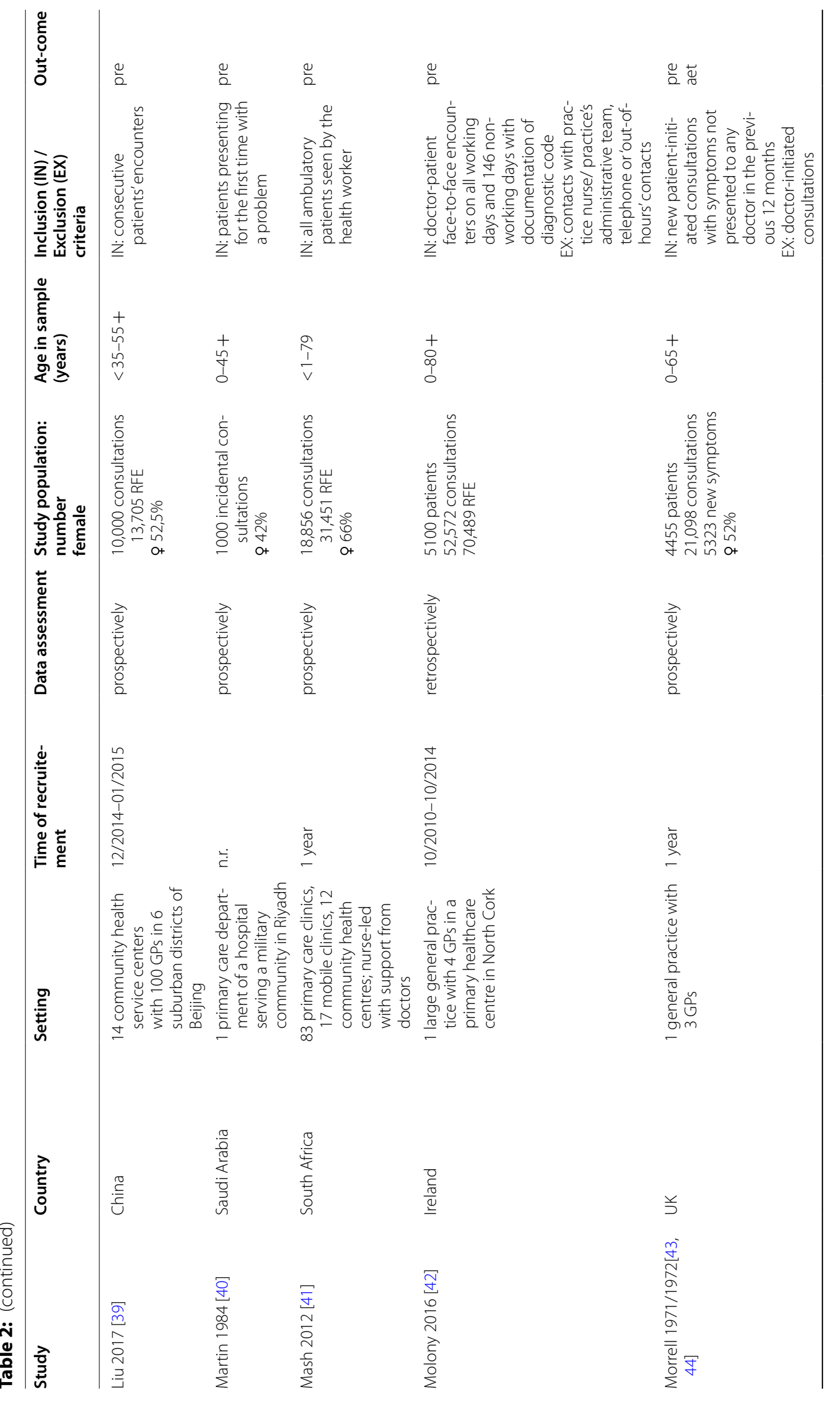




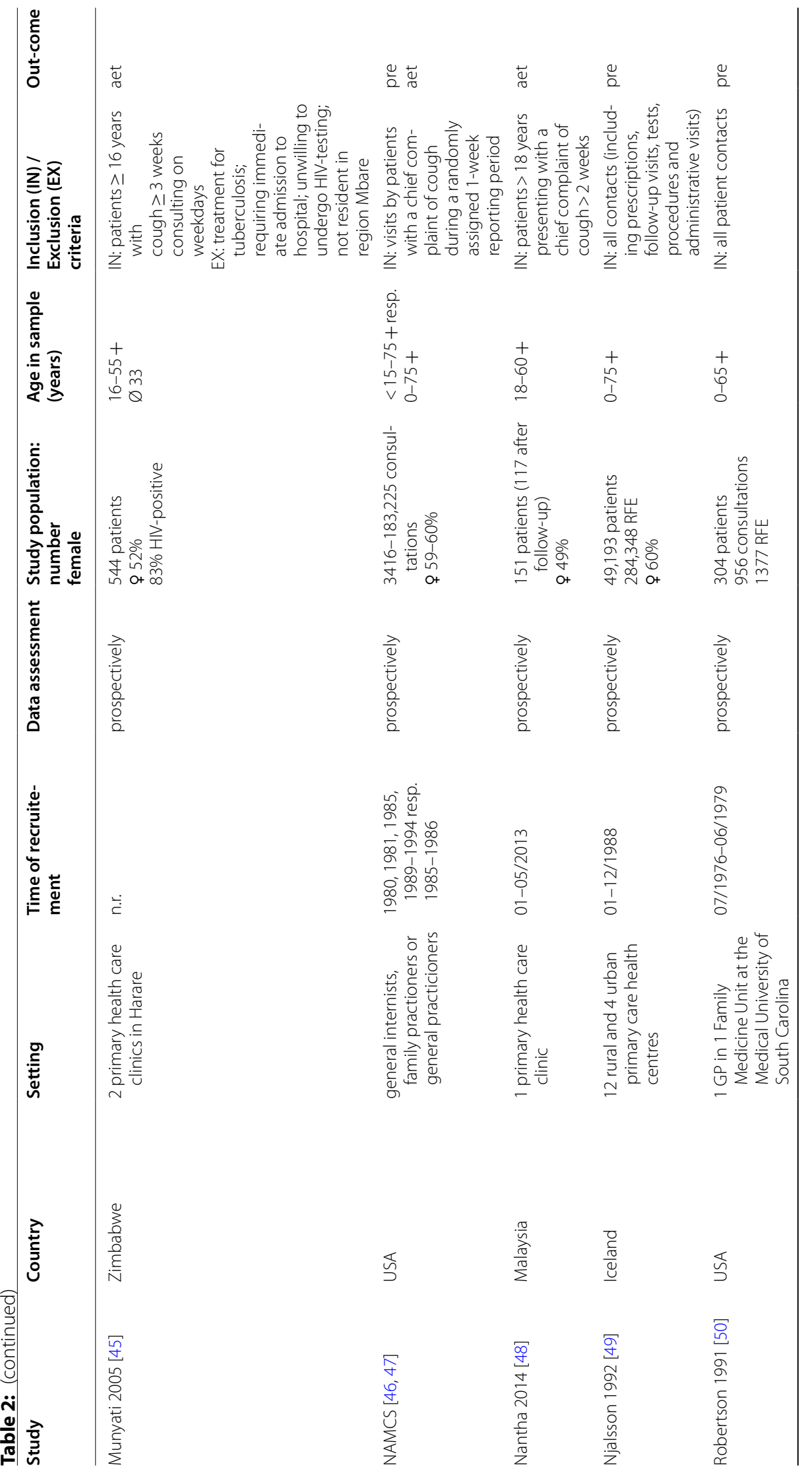




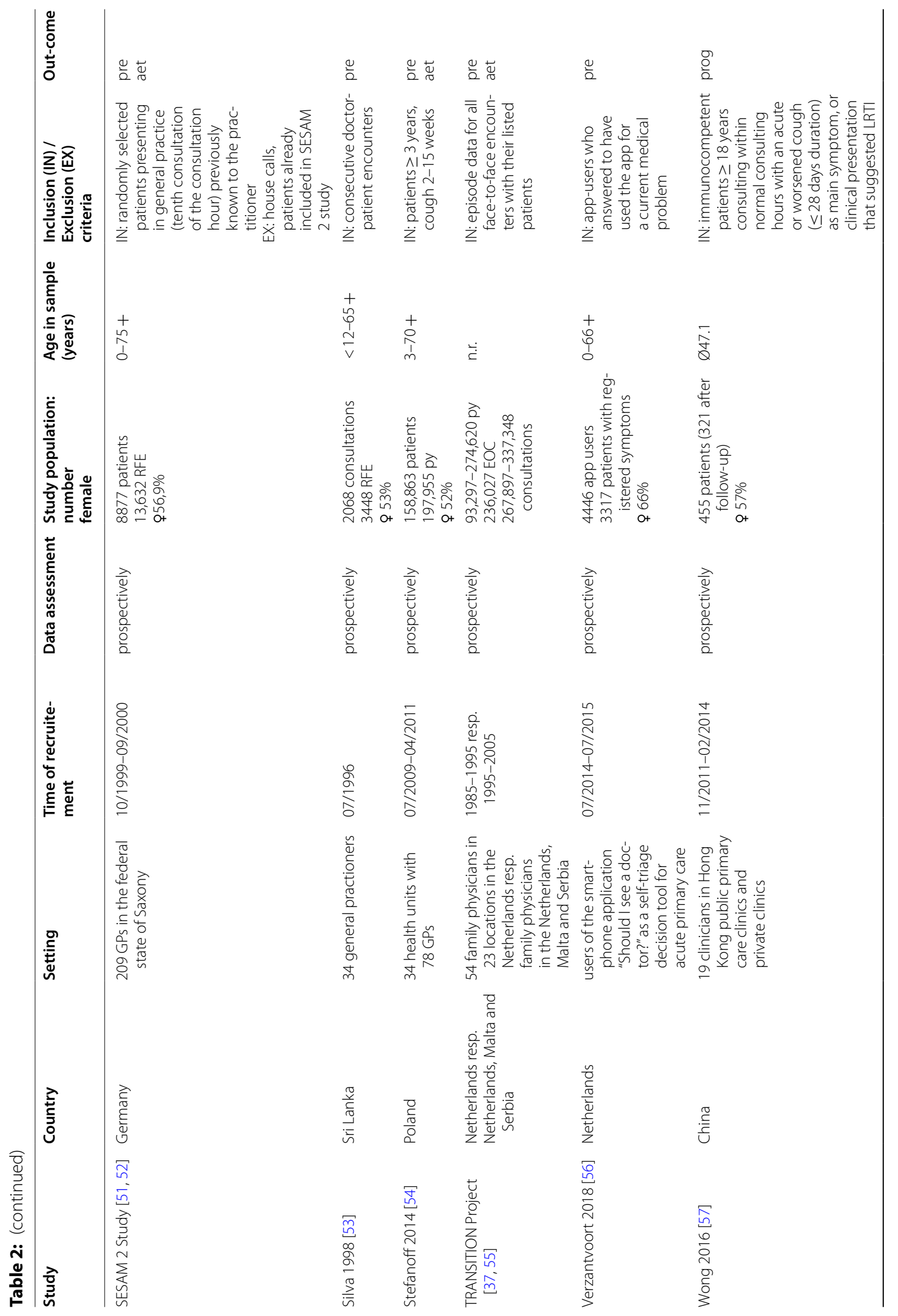




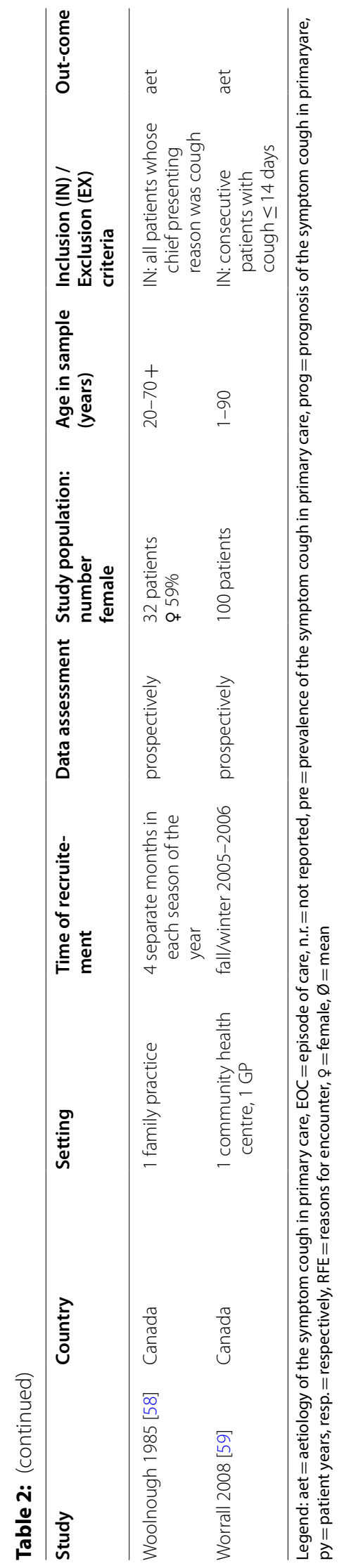


Table 3 Assessment of substantial variation and risk of bias

\begin{tabular}{|c|c|c|c|c|c|}
\hline Domain Study & $\begin{array}{l}\text { A: Substantial variation } \\
\text { in selection of patients } \\
\text { and } \mathrm{GPs}^{1}\end{array}$ & $\begin{array}{l}\text { A: Risk of bias in } \\
\text { selection of patients } \\
\text { and GPs }\end{array}$ & $\begin{array}{l}\text { B: Risk of bias in data } \\
\text { collection and patient } \\
\text { flow }\end{array}$ & $\begin{array}{l}\text { C: Risk of bias } \\
\text { in diagnostic } \\
\text { work-up }{ }^{2}\end{array}$ & $\begin{array}{l}\text { D: Risk of bias } \\
\text { in prognostic } \\
\text { work-up }^{3}\end{array}$ \\
\hline Ajmi 2011 [16] & low & $?$ & low & n.r. & n.r. \\
\hline Albert 2011 [17] & high & high & $?$ & n.r. & n.r. \\
\hline $\mathrm{BEACH}$ & low & low & low & n.r. & n.r. \\
\hline Ben Abdelaziz 2004 [19] & low & $?$ & low & n.r. & n.r. \\
\hline Coenen 2004 [20] & $?$ & low & $?$ & n.r. & $?$ \\
\hline CONTENT & low/?* & $?$ & $?$ & high & n.r. \\
\hline French 2005 [23] & low & high & low & $?$ & n.r. \\
\hline GRACE & ?/high* & low & low/?* & low/?/high* & ?/high* \\
\hline Hamre 2005 [35] & $?$ & low & low & n.r. & low \\
\hline Harding $1980[36]$ & $?$ & low & low & n.r. & n.r. \\
\hline $\begin{array}{l}\text { Hofmans-Okkes } 1993 \\
\text { International Study }\end{array}$ & $?$ & low & low & n.r. & n.r. \\
\hline $\begin{array}{l}\text { Hofmans-Okkes } 1993 \\
\text { Dutch Study }\end{array}$ & $?$ & $?$ & low & n.r. & n.r. \\
\hline Hull 1969 [38] & $?$ & high & low & n.r. & n.r. \\
\hline Liu 2017 [39] & low & high & low & n.r. & n.r. \\
\hline Martin 1984 [40] & high & high & low & n.r. & n.r. \\
\hline Mash 2012 [41] & high & low & low & n.r. & n.r. \\
\hline Molony 2016 [42] & low & high & $?$ & n.r. & n.r. \\
\hline Morrell 1971/1972 [43, 44] & high & high & low & high & n.r. \\
\hline Munyati 2005 [45] & high & high & low & low & n.r. \\
\hline NAMCS & low & low/?* & low/?* & high & n.r. \\
\hline Nantha 2014 [48] & low & high & $?$ & $?$ & n.r. \\
\hline Njalsson 1992 [49] & low & low & $?$ & n.r. & n.r. \\
\hline Robertson 1981 [50] & low & high & low & n.r. & n.r. \\
\hline SESAM 2 & low/high* & low & low & high & n.r. \\
\hline Silva 1998 [53] & low & low & low & n.r. & n.r. \\
\hline Stefanoff 2014 [54] & $?$ & $?$ & $?$ & $?$ & n.r. \\
\hline TRANSITION & low & low & low & high & n.r. \\
\hline Verzantcoort 2018 [56] & high & low & low & n.r. & n.r. \\
\hline Wong 2016 [57] & $?$ & low & $?$ & n.r. & low/?* \\
\hline Woolnough 1985 [58] & $?$ & high & $?$ & low & n.r. \\
\hline Worrall 2008 [59] & low & high & low & high & n.r. \\
\hline
\end{tabular}

Legend: ?= unclear, n.r.= not relevant, $1=$ refers to all included studies, $2=$ refers solely to studies that present data on the underlying aetiologies of cough patients, $3=$ refers solely to studies that present prognostic outcomes, ${ }^{*}=$ varying assessments for different publications or different aetiological /prognostic categories

57]. The follow-up duration was 28 days in all studies, assessed by a symptom diary or telephone interview.

The median duration of cough after first consultation was reported to be eight (IQR 6-14.5) days [30], with the median time to feeling recovered 9 [57] to 11 days. [34] The mean total illness duration was 20.4 days (standard deviation 10) in patients who felt recovered after four weeks [31]. A first improvement of cough was seen the third day after consultation in $52 \%$ of patients [35]. A major improvement or complete recovery was seen in $65.7 \%$ of patients after seven days and in $81.4 \%$ after 14 days [35]. $10.8 \%$ of patients felt completely recovered after seven days [35], 40.2\% [35] to 67\% [32] of patients after 14 days, and 79\% [31] after 4 weeks. A prolonged illness (moderate or severe symptoms more than 3 weeks after consultation), was described in $7.9 \%$ of patients [32]. At day 28 after the first consultation, $21.3 \%$ of patients still didn't feel recovered [31]. The reconsultation rate ranged from $21.1 \%$ [20] to $35 \%$ [30, 32]. Most patients re-consulted the GP during working hours (27.6\%), $1.4 \%$ out of hours, $2.8 \%$ consulted a nurse, $2.7 \%$ a specialist, $0.5 \%$ a hospital emergency department and $17.2 \%$ visited a pharmacist [30]. Between 0\% [30] and $1.3 \%$ [57] of patients were hospitalized for 3-3.5 days 


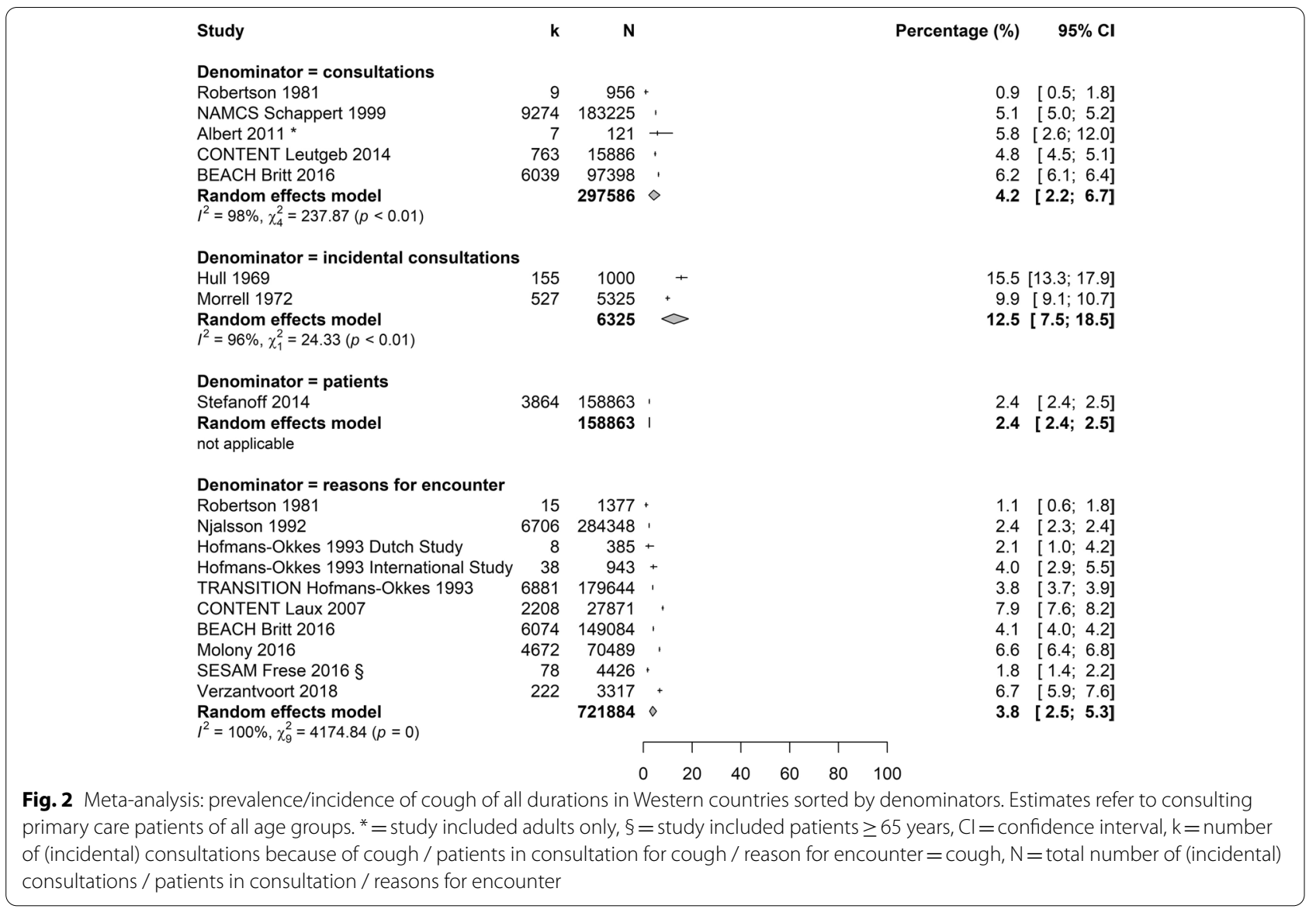

[57] because of cough. No patient died of cough during follow-up [32, 33].

\section{Discussion \\ Main findings}

Our study identified 31 studies evaluating the symptom cough in primary care. Data quality was heterogeneous with only seven studies having an overall low risk of bias. The prevalence of cough in Western primary care was 3.8-4.2\%; the incidence was $12.5 \%$. African, Asian and South American healthcare settings showed higher prevalences (10.3-13.8\%) and lower incidences (6.3-6.5\%). Respiratory tract infection (73-91.9\%) was the most frequent aetiology in patients with acute cough; bronchitis/bronchiolitis was the most frequent aetiology (25.4-50.2\%) in patients with cough of any duration. Other frequent underlying conditions in both were influenza (6-15.2\%), asthma (3.2-15.0\%), and laryngitis/tracheitis (3.6-9.0\%). Serious diseases like pneumonia (4.0-4.2\%), COPD (0.5-3.3\%), heart failure $(0.3 \%)$ and suspected malignancy $(0.2-1.8 \%)$ were rare. Findings on subacute or chronic cough were based on two studies conducted in Zimbabwe and in Malaysia, showing high prevalences of infectious diseases (tuberculosis and pneumonia). For acute cough patients, the median time to feel recovered was 9 to 11 days. Complete recovery was reported by $40.2-67 \%$ of patients after two weeks (79\% after four weeks). 21.1- 35\% of patients re-consulted, $0-1.3 \%$ were hospitalized and none died.

\section{Prevalence}

To our knowledge, there are no other reviews estimating the prevalence or incidence of cough in primary care. However, evidence is needed to set focus in priorities for research, resources, policy making, guideline development and training of primary care professionals [60]. In comparison with our data, the prevalence of cough in population-based surveys is higher (9\% to 33\%) than in primary care [1], most likely due to its self-limiting course. A population-based telephone survey in Italy showed that $23 \%$ of subjects would use domestic remedies, $21 \%$ would ask their pharmacist and only $33 \%$ would consult their doctor [61]. However, when it comes to consultation, for the majority of people (69.6\%-73.7\%) the GP is the first address $[61,62]$. 


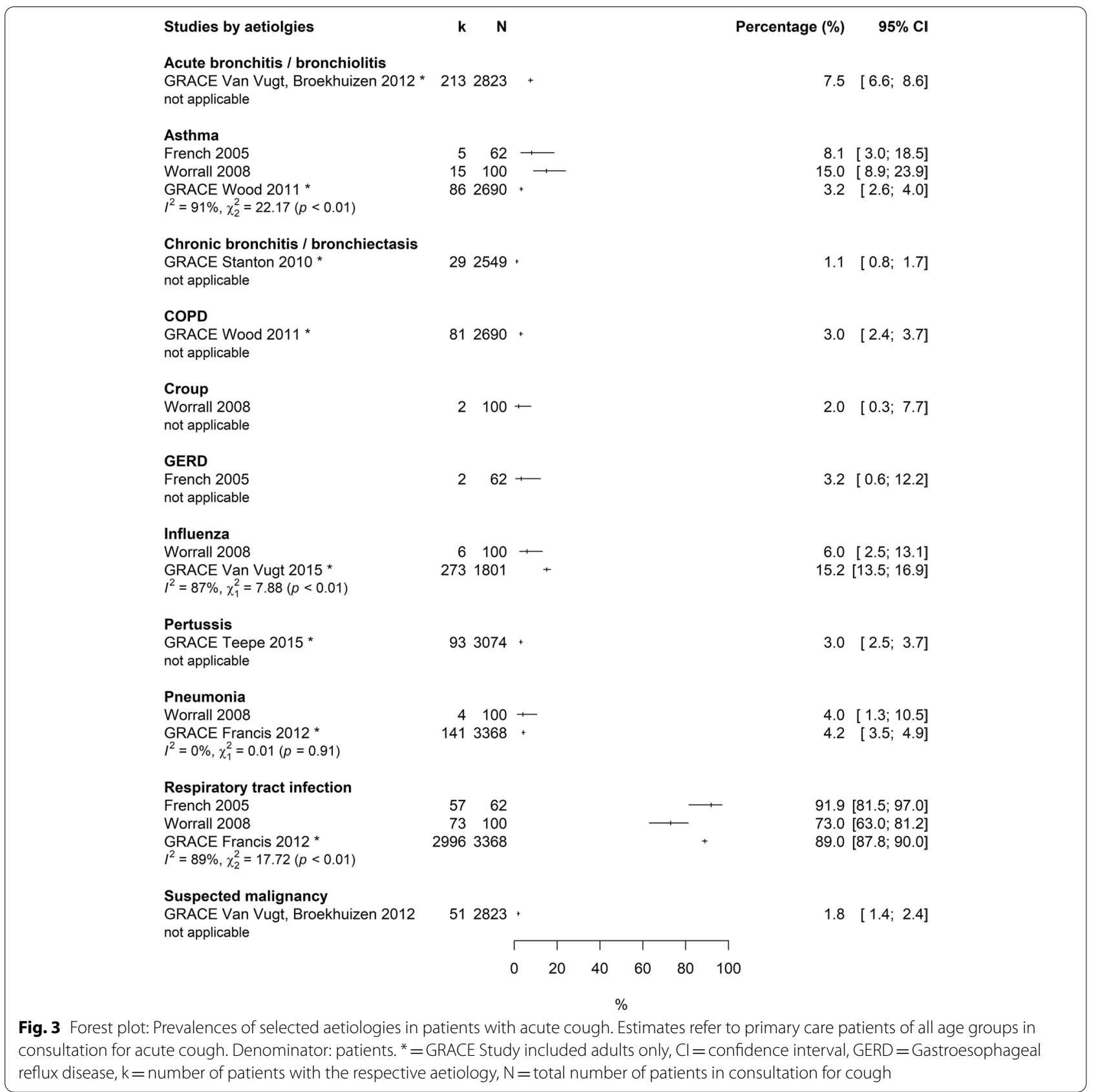

In Western countries, differences between prevalence and incidence estimates were quite high, with prevalences of about $4 \%$ and incidence at $12.5 \%$. This is different in African, Asian and South American primary care settings
(10.3-13.8\% prevalence and $6.3-6.5 \%$ incidence). This might possibly be attributed to the high share of chronic diseases in Western countries, in relation to which cough is less relevant than when compared to a population with

(See figure on next page.)

Fig. 4 Forest plot: Prevalences of selected aetiologies in patients with cough of all durations. Estimates refer to primary care patients of all age groups in consultation for cough of all durations. Denominators: Consultations (NAMCS Metlay 1998), episodes of care (TRANSITION Okkes 2002), incidental consultations (Morrell 1972), reasons for encounter (CONTENT Laux 2007, SESAM Frese 2008), patients (Woolnough 1985). ${ }^{*}=$ studies included adults only, $\mathrm{Cl}=$ confidence interval, $\mathrm{COPD}=$ Chronic obstructive pulmonary disease, $\mathrm{k}=$ number of patients with the respective aetiology, $\mathrm{N}=$ total number of patients in consultation for cough 
Studies by aetiolgies

k N

Percentage (\%) $\quad 95 \% \mathrm{Cl}$

(Acute) bronchitis / bronchiolitis

Morrell $1972 \quad 190 \quad 527$

NAMCS Metlay 1998 * $\quad 14243416$

TRANSITION Okkes $20022817 \quad 11092$

CONTENT Laux $2007 \quad 804 \quad 1600$
$I^{2}=99 \%, \chi_{3}^{2}=597.13(p<0.01)$

Asthma

Woolnough 1985 *

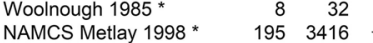

TRANSITION Okkes 200221111092 .

CONTENT Laux $2007 \quad 95 \quad 1600$

SESAM Frese 2008

$I^{2}=99 \%, \chi_{4}^{2}=299.48(p<0.01)$

Chronic bronchitis / bronchiectasis

Morrell $1972 \quad 33 \quad 527$

TRANSITION Okkes 20026711092 .

CONTENT Laux $2007 \quad 511600$ +

SESAM Frese $2008 \quad 45013632$.

$l^{2}=99 \%, \chi_{3}^{2}=308.04(p<0.01)$

COPD

$\begin{array}{lll}\text { TRANSITION Okkes } 2002 & 55 & 11092 \\ \text { CONTENT Laux } 2007 & 36 & 1600\end{array}$ +

$\begin{array}{lrr}\text { CONTENT Laux } 2007 & 36 & 1600 \\ \text { SESAM Frese } 2008 & 450 & 13632\end{array}$

SESAM Frese 2008

Heart failure

TRANSITION Okkes 20023311092 ।

not applicable

$\begin{array}{cl}+ & 36.1[32.0 ; 40.3] \\ + & 41.7[40.0 ; 43.4] \\ + & 25.4[24.6 ; 26.2] \\ + & 50.2[47.8 ; 52.7]\end{array}$

Influenza

Morrell $1972 \quad 35 \quad 527+$

$\begin{array}{lrr}\text { Morrell } 1972 & 35 & 527 \\ \text { NAMCS Metlay } 1998^{*} & 89 & 3416\end{array}$ +

TRANSITION Okkes 200222211092 * $\begin{array}{llr}\text { CONTENT Laux 2007 } & 116 & 1600 \\ \text { SESAM Frese 2008 } & 191 & 13632,\end{array}$

$I^{2}=98 \%, \chi_{4}^{2}=175.65(p<0.01)$

Laryngitis / tracheitis

Morrell 1972

$\begin{array}{lrr}31 & 527 \\ \text { TRANSITION Okkes } 2002 \quad 998 & 11092\end{array}$

CONTENT LaUX 2007

SESAM Frese $2008 \quad 68213632$

$5.0[12.1 ; 43.8]$

$5.7[5.0 ; 6.6]$

$1.9[1.7 ; 2.2]$

$5.9[4.9 ; 7.2]$

$1.1 \quad[0.9 ; 1.3]$

Pertussis

Morrell $1972 \quad 4 \quad 527$

TRANSITION Okkes 20024411092

CONTENT Laux $2007 \quad 31600$

$I^{2}=43 \%, x_{2}^{2}=3.52(p=0.17)$

Pneumonia

Morrell $1972 \quad 10527$ +

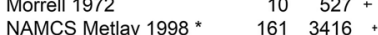

$\begin{array}{llr}\text { NAMCS Metlay } 1998 \text { * } & 161 & 3416 \\ \text { TRANSITION Okkes } 2002 & 211 & 11092 \text {, }\end{array}$

$\begin{array}{lrr}\text { TRANSITION Okkes } 2002 & 211 & 11092 \\ \text { CONTENT Laux } 2007 & 61 & 1600\end{array}$

SESAM Frese $2008 \quad 19113632$

$I^{2}=97 \%, \chi_{4}^{2}=130.79(p<0.01)$

Sinusitis

NAMCS Metlay 1998 * 1913416 +

TRANSITION Okkes $2002 \quad 38811092$ +

CONTENT Laux $2007 \quad 531600+$

CONTENT Laux 2007
$I^{2}=93 \%, x_{2}^{2}=28.46(p<0.01)$

Suspected malignancy

not applicable

Tonsillitis

TRANSITION Okkes 20026711092 ，

CONTENT LAUX 2007

81600 .

$6.6 \quad[4.7 ; 9.2]$

$2.6 \quad[2.1 ; 3.2]$

$2.0[1.8 ; 2.3]$

$7.2[6.1 ; 8.7]$
$1.4 \quad[1.2 ; 1.6]$

$I^{2}=0 \%, \chi_{1}^{2}=0.15(p=0.70)$

Upper respiratory tract infection

Upper respiratory tract infection

$\begin{array}{lrr}\text { Morrell } 1972 & 185 & 527 \\ \text { NAMCS Metlay 1998 * } & 543 & 3416\end{array}$

$\begin{array}{lrr}\text { NAMCS Metlay } 1998 \text { * } & 543 & 3416 \\ \text { TRANSITION Okkes } 20023649 & 11092\end{array}$

$\begin{array}{lrr}\text { TRANSITION Okkes } 2002 & 3649 & 11092 \\ \text { CONTENT Laux } 2007 & 225 & 1600\end{array}$

$l^{2}=100 \%, \chi_{3}^{2}=621.17(p<0.01)$

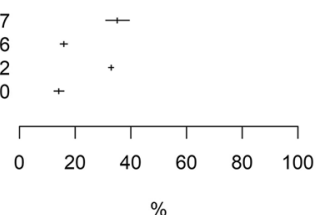

$5.9 \quad[4.1 ; 8.3]$

$9.0 \quad[8.5 ; 9.5]$

$3.6 \quad[2.8 ; 4.7]$

$5.0 \quad[4.6 ; 5.4]$

$0.8 \quad[0.2 ; 2.1]$

$0.4 \quad[0.3 ; 0.5]$

$1.9 \quad[1.0 ; 3.6]$

$4.7 \quad[4.0 ; 5.5]$

$.9[1.7 ; 2.2]$

$3.8 \quad[3.0 ; 4.9]$

$1.4[1.2 ; 1.6]$

$5.6 \quad[4.9 ; 6.4]$

$3.5[3.2 ; 3.9]$

$3.3[2.5 ; 4.3]$

$0.2 \quad[0.1 ; 0.7]$

$0.6 \quad[0.5 ; 0.8]$

$0.5 \quad[0.2 ; 1.0]$

$35.1[31.1 ; 39.4]$

$15.9[14.7 ; 17.2]$

$32.9[32.0 ; 33.8]$

$14.1[12.4 ; 15.9]$

Fig. 4 (See legend on previous page.) 
a high share of acute diseases. Moreover, study outcomes depend on cultural variance between countries (e.g. different healthcare systems, the patient's own health traditions, and different thresholds for consulting a doctor) [14]. In developing countries with a higher rate of uninsured people and fewer health care providers (especially in rural areas) there are fewer consultations for selflimiting acute respiratory tract infections. Furthermore, environmental factors associated with poverty (cooking on an open fire and a higher burden of HIV-infections, accompanied by higher rates of tuberculosis) increase the prevalence of chronic cough.

\section{Aetiology}

International guidelines suggest classifying cough according to its duration, as either acute ( $<3$ weeks), subacute (3-8 weeks), or chronic cough (> 8 weeks) $[5,6,63$, $64]$, or as acute and chronic cough [7, 65-67]. In fact, the most common definition for chronic cough is $\geq 3$ months duration [68]. A categorisation seems necessary as acute cough is mostly caused by a respiratory tract infection, usually vanishing within two weeks [1]. In contrast, chronic cough is associated with a greater risk of serious diseases that require efficient treatment or referral [6]. This is confirmed by our results: we found respiratory tract infections to be the most common underlying conditions of acute cough, followed by exacerbations of asthma and influenza. This is in accordance with primary care guidelines recommending that laboratory tests, sputum evaluation, chest $\mathrm{x}$-rays, and antibiotic treatment all be foregone when respiratory tract infection is clinically likely and no warning signs of serious disease are present [69].

Our results concerning aetiologies of chronic cough are based mainly on two studies from Malaysia [48] and Zimbabwe [45], with a cough $>2 / \geq 3$ weeks. Other than a study from Poland, assessing the prevalence of pertussis [54], we didn't find any evidence for chronic cough in Western primary care and none concerning subacute cough. Our data do not confirm the big three causes of chronic cough (Chronic upper airway cough syndrome, asthma, and gastroesophageal reflux disease (GERD), nor any other differential diagnosis. The respective recommendations on subacute or chronic cough are based on secondary or tertiary care studies $[6,70]$. In fact, given the different case mix, it is likely that the distribution of causes is different in primary care.

\section{Prognosis}

Accurate prediction of the course of cough could decrease antibiotic overprescribing $[71,72]$. Half of antibiotic prescriptions for acute respiratory conditions in US ambulatory care visits seem to be unnecessary [73].
About 53\% of acute cough patients in Europe receive antibiotics [34] - despite the high prevalence of underlying self-limiting viral infection [6,74]. We found no death, a low rate of hospital admissions, an improvement in half of patients after three days and complete recovery in $79 \%$ of patients after one month. A benign course of acute cough was also found by Bruyndonckx et al. [71]. A systematic review assessing primary, secondary, and tertiary care found a weighted mean duration of any cough of 17.8 days (range 15.3 to 28.6 days) and 13.9 days for productive cough (range 13.3 to 17.4 days) [75]. In our study the mean total illness duration was 20.4 days (standard deviation 10). As for acute cough, symptom control without diagnosis ('wait and see approach') seems more sensible than investing in unnecessary diagnostic resources [76]. To reassure patients with low risk, and to confine patients with a high risk of complication, primary care prediction tools like RISSC85 [71] are helpful.

We didn't identify any studies presenting evidence on prognostic outcomes concerning subacute or chronic cough in primary care; this should be addressed in future research.

Guidelines define cough of more than eight weeks as chronic $[6,63,64]$. In fact, the longest follow-up in prognostic studies was 28 days. Outcome assessment varied vastly across prognostic studies; accordingly, standardization seems mandatory. None of the included prognostic studies contained an untreated or alternative control group, leading to a high risk of bias.

\section{Strength and limitations of our study}

Our work comes at a time when the epidemiology of cough has shifted due to the Covid 19 pandemic. Struyf et al. [77] performed a systematic review over the accuracy of Covid-19 symptoms in primary care and in hospital outpatient settings. They identified 44 studies, including three from primary care settings. In a sample including $21 \%$ patients suffering from Covid 19 , they found $65 \%$ of patients presenting with cough, of whom 142 would have Covid-19. The search strategy (searching for Covid-19 studies) was different from our study design and symptoms were actively asked for, so frequencies are overestimated. But even if the study had fit our requirements, these data would be outliers. During a pandemic, the prevalence of diseases and symptoms shifts. In addition, the utilization behaviour, the diagnostics and the frequency of aetiologies as well as the morbidity change. Interventions related to Covid-19 like facial masks are displacing diseases such as influenza and, at the same time, pneumonia is increasing as a cause of cough due to viral illness. Studies conducted during the pandemic are not comparable to the everyday situation of a family practice, which we would like 
to depict in our review. We must point out that the results of our study apply only to the periods leading up to the pandemic. After that, it will be important to examine whether behavioural changes (such as refraining from shaking hands) as a result of the pandemic will change the observed epidemiological data in our study.

Apart from this temporal classification, we must consider the typical weaknesses of a systematic review. Conclusions of any systematic review can only be as valid as the available literature and the accuracy of the included studies' protocols [75]. Important aspects are (1) limitations to the internal validity of the included studies (e.g. imprecise inclusion criteria or incomplete recruitment); (2) criteria affecting the external validity of the included studies (e.g. characteristics of the setting, or recruitment practice); (3) methodological aspects of our review affecting the internal validity of our review (e.g. accuracy in literature search, screening process or data analysis); (4) aspects influencing the review's external validity $[10,13]$.

Accordingly, we performed strict quality assessment and implemented clear inclusion criteria. Our research was comprehensive and thorough, with almost all abstracts and full texts screened by two reviewers. To minimize selection bias, we excluded all studies that explicitly included or excluded certain groups of cough patients and we contacted study authors to acquire missing information. Still, in some cases uncertainty remained regarding eligibility criteria, definition of outcomes or denominators of given data. This may have introduced error into our data synthesis.

We didn't control the risk of bias across studies and the publication bias, as the number of studies concerning the respective outcome was too low. However, it is rather unlikely that prevalences of cough or underlying conditions are not published.

Limitations to our review are the substantial methodological and clinical heterogeneity across included studies. As Higgins et al. postulated "every amount of heterogeneity is acceptable, providing both that the predefined eligibility criteria for the meta-analysis are sound and that the data are correct" [78]. We built subgroups referring to denominators, duration of cough and cultural variances in healthcare systems. In aetiological outcomes, the formation of categories was difficult and overlapping of categories is likely. Given (sub-)categories differed widely. Denominators weren't always specified, which may have influenced data synthesis.

The attribution of countries to the subgroups Western resp. African/Asian/South American countries corresponds with the United Nations classification system of developed and developing countries [79]. We didn't use the latter terms, because people's health demands depend not only on the economic situation of a country, but also on health systems, people's health convictions and utilization of health care.

The assessment of the methodological quality and the risk of bias should be based on standardized checklists. Yet, there are no published criteria referring to studies evaluating symptoms [13]. Therefore our research group has developed a tool for assessing methodological quality and risk of bias, based on work done by Donner-Banzhoff et al. and on the Standards for the Reporting of Diagnostic Accuracy (STARD) on diagnostic accuracy studies $[8,80]$. Applying our tool, we found an overall low risk of bias in only ten studies with prevalence outcomes and in one study with prognostic outcomes, while there was no such study presenting aetiological results. The latter is caused mainly by the fact that the majority of aetiological studies evaluated clinical diagnoses without a standardised diagnostic approach or follow-up. Despite these limitations, most studies in subgroups had similar results, and we think our results are currently the best approach wehave to guide the GP in his everyday decisions.

Statistical limitations can be quantified. Contentrelated aspects can only be discussed and made transparent. We discussed seasonal effects and differences between countries. We ourselves see no reason to exclude older studies as long as they meet the inclusion criteria, and as long as their sample shows an appropriate external validity. This would be different if we knew of any event that calls into question the epidemiological situation at the time, but as far as we know there is nothing we have to consider. If we were already 10 years further along, we would probably exclude the studies of today because of the special situation under pandemic conditions.

\section{Conclusions}

In conclusion, we found cough to be a common reason for consulting in primary care. In the majority of patients presenting for an acute cough, underlying conditions are respiratory tract infections with a benign self-limiting course. About $80 \%$ of these patients show an improvement of symptoms within three days and a complete recovery after 4 weeks, which supports a wait-and-see approach at an early stage of disease. Studies on asthma or influenza show substantial variation of frequencies (3-15\%, resp. 6-15\%). Potentially serious diseases like malignancy or pneumonia occur with less than $1 \%$ (resp. $4 \%$ ) in acute cough. In General Practice the duration of cough is a strong diagnostic tool to distinguish between benign courses and diseases that are more serious. However, since there is no subgroup specific aetiological evidence for prolonged or chronic cough, we cannot capture the changes in pre-test probabilities over time in our data, which is 
mandatory for GPs' diagnostic workup. For future studies, we see a particular need in methodologically sound studies on the cause of subacute and chronic cough in Western primary care. Family physicians need this data to carry out their filtering and pick-up function in the healthcare system. Our study reflects the realities of primary care under non-pandemic conditions. It will be interesting to examine the epidemiological impact of the pandemic on the new normal and compare it with our results.

\section{Abbreviations}

ACE: Angiotensin-Converting-Enzyme; aet: Aetiology; Cl: Confidence Interval; COPD: Chronic Obstructive Pulmonary Disease; EOC: Episode Of Care; GERD: Gastroesophageal Reflux Disease; GP: General Practitioner; n.r.: Not reported; pre: Prevalence; prog: Prognosis; py: Patient years; resp.: Respectively; RFE: Reason For Encounter; o: Female; $\varnothing$ : Mean.

\section{Supplementary Information}

The online version contains supplementary material available at https://doi. org/10.1186/s12875-021-01501-0.

\section{Additional file 1. Detailed search strategy.}

Additional file 2. Assessment of methodological quality, risk of bias and sources of clinical heterogeneity.

Additional file 3. Meta-analysis: Prevalence / incidence of cough in African, Asian and South American countries.

Additional file 4. Aetiologies of subacute and chronic cough.

\section{Acknowledgements}

We would like to thank Thomas Frese, Gunter Laux, Jean Karl Soler and Saskia de Vries-van Vugt for providing information and data.

\section{Authors' contributions}

$M B, J H, D B, S S, K H, S B, P G, L S, A V, N D$ and $A B$ participated in the study design and methodological approach. MB, DB and $\mathrm{JH}$ performed the search and the screening process, MB, KH and SS assessed the studies' quality, clinical heterogeneity and risk of bias. MB collected and analysed data and wrote the manuscript. $A B$ and $J H$ supervised reviewers and discussed the results. $A B$ and $\mathrm{KH}$ commented on this draft and performed critical revisions. All authors read and approved the manuscript.

\section{Funding}

Open Access funding enabled and organized by Projekt DEAL. The study was carried out with own resources (Department for family medicine/primary care, University of Marburg).

\section{Availability of data and materials}

All data analysed during this study were drawn from published articles. The respective references and extracted numbers are all included in this article and its additional information files.

\section{Declarations}

Ethics approval and consent to participate

A systematic review does not require ethical approval.

\section{Consent for publication}

Not applicable.

\section{Competing interests}

The authors declare that they have no competing interests.

Received: 19 July 2020 Accepted: 28 June 2021

Published online: 12 July 2021

\section{References}

1. Chung KF, Pavord ID. Prevalence, pathogenesis, and causes of chronic cough. Lancet Respir Med. 2008;371(9621):1364-74.

2. Chamberlain SAF, Garrod R, Douiri A, Masefield S, Powell P, Bücher C, et al. The Impact of Chronic Cough: A Cross-Sectional European Survey. Lung. 2015;193(3):401-8.

3. Brignall K, Jayaraman B, Birring SS. Quality of Life and Psychosocial Aspects of Cough. Lung. 2008;186(S1):55-8.

4. Dicpinigaitis PV, Colice GL, Goolsby MJ, Rogg GI, Spector SL, Winther B. Acute cough: A diagnostic and therapeutic challenge. Cough. 2009;5:11.

5. Irwin RS, Baumann MH, Bolser DC, Boulet L-P, Braman SS, Brightling $C E$, et al. Diagnosis and management of cough executive summary: ACCP evidence-based clinical practice guidelines. Chest. 2006;129(1 Suppl):1S-23S.

6. Irwin RS, French CL, Chang AB, Altman KW. Classification of Cough as a Symptom in Adults and Management Algorithms: CHEST Guideline and Expert Panel Report. Chest. 2018;153(1):196-209.

7. Morice AH, Millqvist E, Bieksiene K, Birring SS, Dicpinigaitis P, Domingo Ribas C, et al. ERS guidelines on the diagnosis and treatment of chronic cough in adults and children. Eur Respir J. 2020;55(1):1901136.

8. Donner-Banzhoff N, Kunz R, Rosser W. Studies of symptoms in primary care. Fam Pract. 2001;18(1):33-8.

9. Moher D, Liberati A, Tetzlaff J, Altman DG. Preferred reporting items for systematic reviews and meta-analyses: The PRISMA statement. PLoS Med 2009; 6(7):e1000097.

10. Bösner S, Schwarm S, Grevenrath P, Schmidt L, Hörner K, Beidatsch D, et al. Prevalence, aetiologies and prognosis of the symptom dizziness in primary care - a systematic review. BMC Fam Pract. 2018;19(1):33.

11. Haasenritter J, Biroga T, Keunecke C, Becker A, Donner-Banzhoff N, Dornieden $\mathrm{K}$, et al. Causes of chest pain in primary care-a systematic review and meta-analysis. Croat Med J. 2015;56(5):422-30.

12. Stadje R, Dornieden K, Baum E, Becker A, Biroga T, Bosner S, et al. The differential diagnosis of tiredness: a systematic review. BMC Fam Pract. 2016;17(1):147.

13. Viniol A, Beidatsch D, Frese T, Bergmann M, Grevenrath P, Schmidt L, et al. Studies of the symptom dyspnoea: a systematic review. BMC Fam Pract. 2015;16:152.

14. Viniol A, Keunecke C, Biroga T, Stadje R, Dornieden K, Bosner S, et al. Studies of the symptom abdominal pain - a systematic review and metaanalysis. Fam Pract. 2014;31(5):517-29.

15. Cochrane. Cochrane Handbook for Systematic Reviews of Interventions; 2019 [cited 2019 Jul 1]. Available from: URL: www.training.cochrane.org/ handbook.

16. Ajmi TN, Bougmiza I, Zedini C, El GM, Gataa R, Mtiraoui A. Respiratory morbidity in family practice in the region of Sousse. Tunisia East Mediterr Health J. 2011;17(5):431-8.

17. Albert SM, Shevchik GJ, Paone S, Martich GD. Internet-based medical visit and diagnosis for common medical problems: experience of first user cohort. Telemed J E Health. 2011;17(4):304-8.

18. Britt H, Miller GC, Henderson J, Bayram C, Harrison C, Valenti L et al. General practice activity in Australia 2015-2016: BEACH Bettering the Evaluation and Care of Health. GENERAL PRACTICE SERIES 2016 [cited 2017 Jun 28]; (NUMBER 40). Available from: URL: Available at <purl.library. usyd.edu.au/sup/9781743325131>.

19. Ben Abdelaziz A, Krifa I, Hadhri S, Bouabid Z, Daouas F, Msakni N, et al. Healthcare demand in general practice facilities in the Tunisian Sahel. Sante. 2004;14(4):223-9.

20. Coenen S, van Royen P, Michiels B, Denekens J. Optimizing antibiotic prescribing for acute cough in general practice: a cluster-randomized controlled trial. J Antimicrob Chemother. 2004;54(3):661-72.

21. Laux G, Rosemann T, Körner T, Heiderhoff M, Schneider A, Kühlein T, et al. Detaillierte Erfassung von Inanspruchnahme, Morbidität, 
Erkrankungsverläufen und Ergebnissen durch episodenbezogene Dokumentation in der Hausarztpraxis innerhalb des Projekts CONTENT. Gesundheitswesen. 2007;69(5):284-91.

22. Leutgeb R, Laux G, Hermann K, Gutscher A, Szcsenyi J, Kuhlein T. Patient Care in an Out-of-Hours Care Practice - A Descriptive Study of the CONTENT Project. Gesundheitswesen. 2014;76(12):836-9.

23. French CT, Fletcher KE, Irwin RS. A comparison of gender differences in health-related quality of life in acute and chronic coughers. Chest. 2005:127(6):1991-8.

24. Francis NA, Gillespie D, Nuttall J, Hood K, Little P, Verheij T, et al. Delayed antibiotic prescribing and associated antibiotic consumption in adults with acute cough. Br J Gen Pract. 2012;62(602):e639-46.

25. Stanton N, Hood K, Kelly MJ, Nuttall J, Gillespie D, Verheij T, et al. Are smokers with acute cough in primary care prescribed antibiotics more often, and to what benefit? An observational study in 13 European countries. Eur Respir J. 2010;35(4):761-7.

26. Teepe J, Broekhuizen BDL, leven M, Loens K, Huygen K, Kretzschmar M, et al. Prevalence, diagnosis, and disease course of pertussis in adults with acute cough: A prospective, observational study in primary care. Br J Gen Pract. 2015;65(639):e662-7.

27. van Vugt SF, Broekhuizen BD, Zuithoff NP, van Essen GA, Ebell MH, Coenen S, et al. Validity of a clinical model to predict influenza in patients presenting with symptoms of lower respiratory tract infection in primary care. Fam Pract. 2015;32(4):408-14

28. van Vugt S, Broekhuizen L, Zuithoff N, de Jong P, Butler C, Hood K, et al. Incidental chest radiographic findings in adult patients with acute cough. Ann Fam Med. 2012;10(6):510-5.

29. Wood J, Butler CC, Hood K, Kelly MJ, Verheij T, Little P, et al. Antibiotic prescribing for adults with acute cough/lower respiratory tract infection: congruence with guidelines. Eur Respir J. 2011;38(1):112-8.

30. Godycki-Cwirko M, Hood K, Nocun M, Muras M, Goossens H, Butler CC. Presentation, antibiotic management and associated outcome in Polish adults presenting with acute cough/LRTI. Fam Pract. 2011;28(6):608-14.

31. Hordijk PM, Broekhuizen BDL, Butler CC, Coenen S, Godycki-Cwirko $\mathrm{M}$, Goossens $\mathrm{H}$ et al. Illness perception and related behaviour in lower respiratory tract infections-a European study. Fam Pract 2014

32. van Vugt SF, Butler CC, Hood K, Kelly MJ, Coenen S, Goossens H, et al. Predicting benign course and prolonged illness in lower respiratory tract infections: a 13 European country study. Fam Pract. 2012;29(2):131-8.

33. van Vugt SF, Broekhuizen BDL, Lammens C, Zuithoff NPA, Jong PA de, Coenen $S$ et al. Use of serum $C$ reactive protein and procalcitonin concentrations in addition to symptoms and signs to predict pneumonia in patients presenting to primary care with acute cough: diagnostic study. BMJ 2013; 346:f2450.

34. Butler CC, Hood K, Verheij T, Little P, Melbye H, Nuttall J et al. Variation in antibiotic prescribing and its impact on recovery in patients with acute cough in primary care: prospective study in 13 countries. BMJ 2009; 338:b2242.

35. Hamre HJ, Fischer M, Heger M, Riley D, Haidvogl M, Baars E et al. Anthroposophic vs. conventional therapy of acute respiratory and ear infections: a prospective outcomes study. Wien Klin Wochenschr 2005; 117(7-8):256-68

36. Harding TW, de Arango MV, Baltazar J, Climent CE, Ibrahim HH, LadridoIgnacio $L$, et al. Mental disorders in primary health care: a study of their frequency and diagnosis in four developing countries. Psychol Med. 1980;10(2):231-41.

37. Hofmans-Okkes I. An international study into the concept and validity of the \&\#39;reason for encounter\&\#39;

38. Hull FM. Social class consultation patterns in rural general practice. J R Coll Gen Pract. 1969;18(85):65-71.

39. Liu Y, Chen C, Jin G, Zhao Y, Chen L, Du J et al. Reasons for encounter and health problems managed by general practitioners in the rural areas of Beijing, China: A cross-sectional study. PLoS One 2017; 12(12):e0190036.

40. Martin E. Symptoms of patients and escorts in a primary care department in Saudi Arabia. Fam Pract. 1984;1 (2):100-5.

41. Mash B, Fairall L, Adejayan O, Ikpefan O, Kumari J, Matheel S et al. A morbidity survey of South African primary care. PLoS One 2012; 7(3):e32358.

42. Molony D, Beame C, Behan W, Crowley J, Dennehy T, Quinlan M, et al. 70,489 primary care encounters: Retrospective analysis of morbidity at a primary care centre in Ireland. Ir J Med Sci. 2016;185(4):805-11.

43. Morrell DC, Gage HG, Robinson NA. Symptoms in general practice. J R Coll Gen Pract. 1971;21(102):32-43.
44. Morrell DC. Symptom interpretation in general practice. J R Coll Gen Pract. 1972;22(118):297-309.

45. Munyati SS, Dhoba T, Makanza ED, Mungofa S, Wellington M, Mutsvangwa J, et al. Chronic cough in primary health care attendees, Harare, Zimbabwe: diagnosis and impact of HIV infection. Clin Infect Dis. 2005:40(12):1818-27.

46. Metlay JP, Stafford RS, Singer DE. National trends in the use of antibiotics by primary care physicians for adult patients with cough. Arch Intern Med. 1998;158(16):1813-8.

47. Schappert SM, Nelson C. National Ambulatory Medical Care Survey: 1995-96 summary. Vital Health Stat 13 1999; Series 13, Data from the National Health Survey(142):i-vi, 1-122.

48. Nantha YS. Therapeutic-diagnostic Evaluation of Chronic Cough Amongst Adults: Causes, Symptoms and Management at the Primary Care Level Malaysia. J Family Med Prim Care. 2014;3(3):207-12.

49. Njalsson T, McAuley RG. Reasons for contact in family practice. An Icelandic multicentre study on content of practice. Scand J Prim Health Care 1992; 10(4):250-6.

50. Robertson DL. Symptoms encountered during a three-year family practice residency. J Fam Pract. 1981;13(2):239-44.

51. Frese T, Mahlmeister J, Deutsch T, Sandholzer H. Reasons for elderly patients GP visits: Results of a cross-sectional study. Clin Interv Aging. 2016;11:127-32.

52. Frese T, Thiersch S, Voigt R, Dietrich J, Sandholzer H. Husten in der allgemeinärztlichen Sprechstunde - Differenzialdiagnosen unterscheiden sich gegenüber Klinik. Notfall \& Hausarztmedizin. 2008;34(12):596-8.

53. de Silva N, Mendis K. One-day general practice morbidity survey in Sri Lanka. Fam Pract. 1998;15(4):323-31.

54. Stefanoff P, Paradowska-Stankiewicz IA, Lipke M, Karasek E, Rastawicki W, Zasada A, et al. Incidence of pertussis in patients of general practitioners in Poland. Epidemiol Infect. 2014;142(4):714-23.

55. Okkes IM, Oskam SK, Lamberts H. The probability of specific diagnoses for patients presenting with common symptoms to Dutch family physicians. J Fam Pract. 2002;51(1):31-6.

56. Verzantvoort NCM, Teunis T, Verheij TJM, van der Velden AW. Self-triage for acute primary care via a smartphone application: Practical, safe and efficient? PLoS One 2018; 13(6):e0199284.

57. Wong CKM, Liu Z, Butler CC, Wong SYS, Fung A, Chan D, et al. Help-seeking and antibiotic prescribing for acute cough in a Chinese primary care population: A prospective multicentre observational study. NPJ Prim Care Respir Med. 2016;26:15080.

58. Woolnough KV, Ross KM. Cough: bronchospasm or not? Can Fam Physician. 1985;31:499-502.

59. Worrall GJ. One hundred coughs: family practice case series. Can Fam Physician. 2008;54(2):236-7.

60. Finley CR, Chan DS, Garrison S, Korownyk C, Kolber MR, Campbell S, et al. What are the most common conditions in primary care? Systematic review. Can Fam Physician. 2018;64(11):832-40.

61. Dal Negro RW, Mazzolini M, Turco P, Zanasi A. Cough: Impact, beliefs, and expectations from a national survey. Multidiscip Respir Med. 2016;11:34.

62. Schappert SM, Burt CW. Ambulatory care visits to physician offices, hospital outpatient departments, and emergency departments: United States, 2001-02. Vital Health Stat 13 2006; (159):1-66.

63. Kohno S, Ishida T, Uchida Y, Kishimoto H, Sasaki H, Shioya T, et al. The Japanese Respiratory Society guidelines for management of cough. Respirology. 2006;11(Suppl 4):S135-86.

64. Lai K, Shen H, Zhou X, Qiu Z, Cai S, Huang K, et al. Clinical Practice Guidelines for Diagnosis and Management of Cough-Chinese Thoracic Society (CTS) Asthma Consortium. J Thorac Dis. 2018;10(11):6314-51.

65. Morice AH, Fontana GA, Sovijarvi ARA, Pistolesi M, Chung KF, Widdicombe J, et al. The diagnosis and management of chronic cough. Eur Respir J. 2004;24(3):481-92.

66. Kardos P, Dinh QT, Fuchs K-H, Gillissen A, Klimek L, Koehler M, et al. Guidelines of the German Respiratory Society for Diagnosis and Treatment of Adults Suffering from Acute, Subacute and Chronic Cough. Pneumologie. 2019;73(3):143-80.

67. Cough (acute): antimicrobial prescribing: NICE guideline [NG120]; 2019 [cited 2019 Feb 2]. Available from: URL: https://www.nice.org.uk/guida nce/ng120. 
68. Song W-J, Chang Y-S, Faruqi S, Kang M-K, Kim J-Y, Kang M-G, et al. Defining Chronic Cough: A Systematic Review of the Epidemiological Literature. Allergy Asthma Immunol Res. 2016;8(2):146-55.

69. Holzinger F, Beck S, Dini L, Stoter C, Heintze C. The diagnosis and treatment of acute cough in adults. Dtsch Arztebl Int. 2014;111(20):356-63.

70. Beck S, Dini L, Heintze C, Holzinger F, Stöter C. Husten: DEGAM-Leitlinie Nr. 11; 2014 [cited 2019 Mar 14]. Available from: URL: https://www. degam.de/degam-leitlinien-379.html.

71. Bruyndonckx R, Hens N, Verheij TJ, Aerts M, leven M, Butler CC, et al. Development of a prediction tool for patients presenting with acute cough in primary care: A prognostic study spanning six European countries. Br J Gen Pract. 2018;68(670):e342-50.

72. O'Connor R, O'Doherty J, O'Regan A, Dunne C. Antibiotic use for acute respiratory tract infections (ARTI) in primary care; what factors affect prescribing and why is it important? A narrative review. Ir J Med Sci 2018; 187(4):969-86.

73. Fleming-Dutra KE, Hersh AL, Shapiro DJ, Bartoces M, Enns EA, File TM, et al. Prevalence of Inappropriate Antibiotic Prescriptions Among US Ambulatory Care Visits, 2010-2011. JAMA Journal of the American Medical Association. 2016:315(17):1864.

74. Aabenhus R, Hansen MP, Saust LT, Bjerrum L. Characterisation of antibiotic prescriptions for acute respiratory tract infections in Danish general practice: a retrospective registry based cohort study. NPJ Prim Care Respir Med. 2017;27(1):37.
75. Ebell MH, Lundgren J, Youngpairoj S. How long does a cough last? Comparing patients' expectations with data from a systematic review of the literature. Ann Fam Med. 2013;11(1):5-13.

76. Dinant G-JGJ, Buntinx FF, Butler CCC. The necessary shift from diagnostic to prognostic research. BMC Fam Pract 2007; 8(1):974.

77. Struyf T, Deeks JJ, Dinnes J, Takwoingi Y, Davenport C, Leeflang MM et al. Signs and symptoms to determine if a patient presenting in primary care or hospital outpatient settings has COVID-19. Cochrane Database Syst Rev 2021; 2:CD013665.

78. Higgins JPT. Commentary: Heterogeneity in meta-analysis should be expected and appropriately quantified. Int J Epidemiol. 2008;37(5):1158-60.

79. United Nations - Department of Economic and Social Affairs - Development Policy and Analysis Division. World Economic Situation and Prospects 2018: United Nations - Department of Economic and Social Affairs - Development Policy and Analysis Division; 2018 [cited 2020 Apr 21]. Available from: URL: https://www.un.org/development/desa/dpad/ wp-content/uploads/sites/45/publication/WESP2018_Full_Web.pdf.

80. Bossuyt PM. Towards complete and accurate reporting of studies of diagnostic accuracy: The STARD initiative. Family Practice. 2004;21(1):4-10.

\section{Publisher's Note}

Springer Nature remains neutral with regard to jurisdictional claims in published maps and institutional affiliations.
Ready to submit your research? Choose BMC and benefit from:

- fast, convenient online submission

- thorough peer review by experienced researchers in your field

- rapid publication on acceptance

- support for research data, including large and complex data types

- gold Open Access which fosters wider collaboration and increased citations

- maximum visibility for your research: over $100 \mathrm{M}$ website views per year

At BMC, research is always in progress.

Learn more biomedcentral.com/submissions 